\title{
Acesso e Transição nos Níveis Representacionais durante a Construção de Modelos Explicativos acerca de Interações Intermoleculares
}

\section{Access and Transitions Between Representational Levels in the Construction of Explanatory Models Concerning Intermolecular Interactions}

B(10) Bruno Gumieri Fernandes, ${ }^{10}$ Solange Wagner Locatelli Palavras-chave
Ensino de Química;
Níveis
representacionais;
Visualizações;
Metavisualização;
Interações
intermoleculares.
Resumo A química pode ser compreendida por meio de três níveis representacionais: macro, submicro e o simbólico, sendo que a relação entre eles precisa ser adequadamente estabelecida. Visando investigar esses aspectos, essa pesquisa teve como objetivo compreender os níveis representacionais acessados pelos alunos, suas dificuldades e o papel da estratégia metavisual durante a elaboração de modelos explicativos acerca de interações intermoleculares. Para isso, participaram 3 graduandos de uma universidade pública brasileira, durante a disciplina de Práticas de Ensino de Química II. Todo o processo foi documentado com base em gravações audiovisuais, contemplando a técnica "think aloud", em que os alunos analisados criaram desenhos propondo modelos explicativos para misturas, considerando-se as interações intermoleculares presentes. Posteriormente, foram feitas as transcriçõoes e a partir delas, algumas categorizações. Os resultados indicaram que os alunos conseguiram fazer transições entre os níveis, sendo mais preponderantes as transições referentes ao submicro, mesmo sendo o de maior abstração. Utilizaram o macro de forma reflexiva, possibilitando transições com o submicro para validação de modelos, enquanto para o simbólico foram apresentados entraves relacionados às representações. Com relação à atividade metavisual, inferiu-se que contribuiu de forma satisfatória no entendimento dos níveis representacionais, uma vez que possibilitou um intenso exercício metacognitivo de construção e reconstrução de conceitos científicos. Finalizando, neste trabalho foi proposto um novo modelo de categorização para os níveis representacionais, considerando-se tanto o acesso como a transição nos níveis representacionais.

Submetido em 11 de abril de 2020 Aceito para publicação em 17 de dezembro de 2020 Publicado em 04 de março de 2021 
Keywords Abstract Chemistry can be understood through three Chemistry teaching; representational levels: macro, submicro and symbolic, and the Representational relationship between them needs to be properly established. In order

levels; to investigate these aspects, this research aimed to understand the Visualizations; representational levels accessed by students, their difficulties and the Metavisualization; role of a metavisual strategy during the development of explanatory Intermolecular models on intermolecular interactions. For this, three undergraduate interactions. students from a Brazilian public university participated during the course of Chemistry Teaching Practices II. The entire process was documented based on audiovisual recordings, contemplating a "thinkaloud" technique, in which students draw up explanatory models for mixtures, considering the intermolecular interactions present. Later, transcriptions were made followed by some categorizations. The results indicated that the students were able to make transitions between the levels, the most important being those related to submicro transitions, even though this is the one with the greatest abstraction. They used the macro level reflexively, allowing transitions with the submicro one for model validation, while the symbolic level was linked to difficulties associated to representations. Regarding the metavisual activity, it was inferred that it contributes adequately to the understanding of the representational levels, since it enabled an intense metacognitive exercise of construction and reconstruction of scientific concepts. Finally, a new categorization model was proposed for the representational levels, considering both access and transition between representational levels.

\section{Introdução}

O desenvolvimento do conhecimento pelo sujeito se constitui, basicamente, por certas aproximações deste ao objeto, ou seja, de como ele o constrói, melhorando suas noções e transpassando de estágios inferiores, para superiores de conhecimento (Mortimer, 2000). Ainda de acordo com esse autor, a ciência, como uma miscelânea de saberes, precisa se aproximar do cotidiano das pessoas. Além disso, deve se referir também ao universo do indivíduo, para que assim ele possa construir algo mais amplo, agregando também aspectos dos conhecimentos universais.

Considerar que os alunos não detenham nenhuma bagagem não se mostra adequado, uma vez que eles trazem informações para a sala de aula que, na maioria das vezes, vêm de suas vivências. Os professores do Ensino Superior, por exemplo, geralmente utilizam o modelo de ensino tradicional (Schnetzler, 2002) que se pauta, principalmente, em um processo passivo, em que o aluno é considerado um receptáculo vazio a ser preenchido, com transmissão de conhecimento por parte do professor e de recepção dessas informações por parte desses alunos (Gibin \& Ferreira, 2010). Além disso, muitas 
vezes os conteúdos químicos são transmitidos como inquestionáveis, sendo pautados em experimentos tabulados e referidos pela literatura acadêmica mundial, ocasionalmente isentos de contextos e visões dos sujeitos que os realizaram (Schnetzler, 2002). Sendo assim, dificulta a discussão ou questionamento de certos pontos já estabelecidos, com as diversas teorias sendo colocadas como verdade absoluta, ou ainda, os conteúdos são apresentados em um contexto aquém de alguma aplicação, não fazendo parte do dia a dia do aluno, tampouco trazendo significado a ele (Gibin \& Ferreira, 2010).

A partir do momento em que o professor começa a considerar as concepções trazidas pelos alunos, ele passa a se aproximar das mesmas, de forma individualizada, conseguindo em muitos momentos construir algo que ajude na construção do aprendizado (Mortimer, 2000). A ideia não é acabar com suas concepções e forçar o conhecimento científico, ao invés disso, fazer com que haja reconstrução de seus conhecimentos prévios, com assimilação e acomodação das novas experiências e conhecimentos a essas concepções, possibilitando a construção de conceitos científicos.

Com base no contexto do Ensino Superior, um bacharel ou licenciado em química, segundo as Diretrizes Curriculares Nacionais para os Cursos de Química, deve entre os diversos objetivos, "conhecer as propriedades físicas e químicas principais dos elementos e compostos, que possibilitem entender e prever o seu comportamento físicoquímico, aspectos de reatividade, mecanismos e estabilidade" (Brasil, 2001, p. 7), o que leva a uma necessidade por uma formação sólida deste profissional no que se refere ao entendimento das diversas interações e transformações da matéria e para isso, almeja-se um ensino que leve em conta a criação de modelos mentais, auxiliando na compreensão desses aspectos.

Para isso, é importante se pautar em sequências didáticas, que façam os alunos construírem e repensarem, a todo momento, o seu processo de aprendizagem sobre determinado assunto ou conceito. Nesse contexto, sequências didáticas que envolvem práticas metacognitivas auxiliam, principalmente, no acesso as concepções e conhecimento relacionado à construção de modelos mentais, por exemplo, no que diz respeito aos conceitos das interações que ocorrem entre as moléculas. Vale ressaltar que os modelos mentais são utilizados para caracterizar, compreender e explicar como certos fenômenos e observações ocorrem, sendo um processo de construção interna de cada indivíduo, ou seja, correspondem ao modo como as pessoas visualizam os fenômenos químicos (Gibin \& Ferreira, 2010).

Assim, foi proposto aos discentes elaborarem modelos explicativos acerca de interações intermoleculares presentes entre compostos, sendo as seguintes perguntas norteadoras dessa pesquisa:

Quais os níveis representacionais acessados pelos discentes? Como é esse acesso? Quais as dificuldades manifestadas por eles? Como que uma estratégia metavisual pode auxiliar na identificação e compreensão dos níveis representacionais acessados pelos discentes? 


\section{Níveis representacionais e o Ensino de Química}

Segundo Johnstone (1993, p. 703, tradução nossa), a química pode ser interpretada por meio de três componentes básicos para a sua compreensão, o nível "macroquímico, o submicroquímico e o representacional químico".

A concepção de níveis (macroquímico, submicroquímico e representacional químico) é reconhecida entre os autores do Ensino de Química, porém não há uma terminologia aceita universalmente por todos. Gilbert e Treagust (2009, p. 6, tradução nossa), modelo que orientará o presente trabalho, utilizam como terminologia "macro, submicro e simbólico" para cada um dos respectivos níveis.

O nível macro representa os fenômenos que são observáveis como, experimentos e fenômenos sensoriais. Já o nível submicro envolve modelos e construções em nível molecular para explicar os aspectos macro, como moléculas, átomos, íons e elétrons. Por fim, o nível simbólico compreende a linguagem empregada pelos químicos como equações químicas e símbolos de elementos.

Em uma revisão sobre os níveis representacionais em química, Wartha et al. (2012) propõem um experimento em eletroquímica considerando, na sequência de ensino, abordagens que possibilitem a conexão dos três níveis de representação. Dessa forma, promovem a integração entre eles, permitindo que os estudantes constituam uma visão de totalidade, minimizando a complexidade na transição entre os níveis. Nesse sentido, Santos e Arroio (2016) trazem como resultado de sua pesquisa, a dificuldade apresentada por alunos, tanto do Ensino Médio como Superior, acerca do entendimento dos três níveis representacionais, sendo o submicro ainda o de maior entrave. Ainda, em um contexto de aula em laboratório de química, Keiner e Graulich (2019) também discutem a dificuldade de relacionar e conectar os três níveis representacionais, especialmente no ambiente de laboratório, em que é necessário recorrer aos modelos explicativos do nível submicro, para a compreensão do fenômeno que está sendo observado (macro).

Vale mencionar que um dos obstáculos na compreensão dos níveis, se encontra nas transições entre eles. Por exemplo, nas esferas relacionadas ao submicro e ao simbólico (Chittleborough \& Treagust, 2008; Gibin \& Ferreira, 2010), bem como nas transições entre os níveis macro e submicro. Com relação a esse último, as diferenças de escalas podem se tornar uma barreira, exigindo do aluno uma habilidade de abstração que muitas vezes é precária ou inexistente (Chittleborough \& Treagust, 2008). Assim, as representações concretas se demonstram mais táteis à sua compreensão do que representações ou modelos abstratos, que passam por não gerar sentido (Ferk et al., 2003). Como no nível submicro, o aluno não consegue visualizar o que ocorre, ele passa a apresentar dificuldades na criação de abstrações, diferente de fenômenos tangíveis e concretos, em que ele consegue acompanhar pelos sentidos (Locatelli \& Arroio, 2011). Concernente a isso, Locatelli e Arroio (2017) perceberam que os alunos passaram a conectar-se às explicações inerentes ao nível submicro, quando manifestaram indícios de repensar no nível macro, possibilitando assim, repensar aspectos do submicro, visando a compreensão dos conteúdos químicos, o que reforça a necessidade de integração entre 
os níveis.

Segundo Chittleborough e Treagust (2008), para graduandos com pouco ou sem nenhum conhecimento de fundo químico, os diagramas do nível submicro de representação são mais difíceis de interpretar e os alunos acabam por demonstrar "modelos mentais pobres do nível submicroscópico da matéria" (p. 464). Com relação a isso, Gibin e Ferreira (2010, p. 1810) também discutem e trazem de forma clara a construção de modelos mentais e seus principais obstáculos:

As principais características dos modelos mentais são: incompletos geralmente as pessoas possuem a habilidade de "executar" seus modelos mentais de forma muito limitada; são instáveis - as pessoas esquecem detalhes do modelo; não têm fronteiras bem definidas - operações e conceitos semelhantes são confundidos; são "não científicos" - as pessoas mantêm padrões de comportamento "supersticiosos", mesmo quando sabem que não são necessários, assim, os modelos mentais de uma pessoa refletem suas crenças sobre o sistema em estudo e, por fim, são econômicos — os modelos elaborados tendem a ser o mais simples possível. Dessa forma, em investigações sobre modelos mentais é importante esperar que os modelos apresentados possam ser equivocados, ambíguos e incompletos.

Apesar da complicação acerca do nível submicro, Al-Balushi (2013), pesquisando sobre professores em formação (como em nossa pesquisa) e discutindo sobre a transição entre os níveis, sinaliza que a representação no submicro passou a facilitar a aprendizagem do fenômeno, bem como a tecer previsões sobre ele, evidenciando a importância de uma adequada compreensão do nível submicro.

No que diz respeito às dificuldades no simbólico, é proposto que a linguagem química seja articulada a um contexto e não se constitua apenas de palavras estranhas e sem sentido (Flôr \& Cassiani, 2016). Se isso ocorrer, as representações não são entendidas em termos moleculares, e os alunos podem se utilizar desta simbologia de maneira mecânica, não conseguindo diferenciar a simbologia de uma molécula ou de um íon, por exemplo (Cedran et al., 2018). Portanto, a transição de representação entre o submicro e simbólico, por exemplo, pode muitas vezes se tornar um obstáculo preponderante para o aluno, como discutem Taber (2009) e Cedran et al. (2018) ao afirmarem que para compreensão dessas transições, tanto a simbologia química como a demanda cognitiva são complexas, necessitando de uma articulação entre contextos.

Os químicos então, de uma maneira geral, lançam mão da adição de estímulos visuais e modelos que fazem com que eles melhorem e desenvolvam a capacidade de construção de seu próprio modelo mental, ajudando na visualização das entidades e na criação de relações, causas e efeitos (Locatelli \& Arroio, 2011).

Conceitos químicos, que se pautam principalmente em aspectos do submicro, são aqueles que necessitam de uma relevância em relação a criação e elaboração de modelos, como o conceito de interações intermoleculares. Compreender de fato as interações que ocorrem entre as moléculas de um ou mais compostos, com a finalidade 
de prever uma propriedade química ou física, por exemplo, é algo difícil e que demanda níveis de abstração muito específicos, sendo muitas vezes ainda mais complicado devido as diversas concepções criadas ao longo da vida escolar. Esse é um conceito que não é muito compreendido, por se tratar de um ensino que exige abstração e que depende da habilidade visual.

Um último aspecto a ser considerado dentro dessa discussão sobre o enredamento concernente aos níveis representacionais, refere-se à expertise dos estudantes. Gomez, Pozo e Sanz (1995) complementam que os alunos mais experientes tendem a demonstrar mais consistência com relação aos conceitos científicos do que os menos experientes, já que um percurso acadêmico maior promove ao aluno contatos maiores com situações, problemas, conceitos e estratégias, podendo assim auxiliar no desenvolvimento das habilidades requeridas para uma melhor compreensão da química. Santos, Lima e Sarmento (2017), por exemplo, discutem sobre o conhecimento químico de graduandos no início do curso de licenciatura e percebem que a compreensão em relação ao nível submicro é frágil, trazendo às vezes alguns aspectos ao submicro de um conhecimento básico do Ensino Médio, ou então inexistente, já que se apoiam principalmente no nível macro. Nesse caminho, reforçando o percurso e a vivência acadêmica, Kozma e Russel (2005) acreditam que os alunos não apresentam desenvolvimento automático no que diz respeito à competência representacional, ao invés disso, essas habilidades seguem o que ele denomina de "uma trajetória de desenvolvimento" (p. 132, tradução nossa).

\section{Algumas concepções em relação ao conceito de interações intermoleculares}

No escopo das interações intermoleculares, podemos encontrar diversas concepções que, ao longo da vida escolar, passam a gerar obstáculos epistemológicos em relação ao Ensino de Química, se postergando até o Ensino Superior (Francisco Junior, 2008; Rodrigues et al., 2011). Dentre os principais obstáculos, percebe-se a associação entre interações intermoleculares e misturas, em que substâncias de diferentes composições passam a apresentar interações entre suas diversas moléculas, porém são desconsideradas as interações entre as moléculas de uma mesma substância. Francisco Junior (2008) acrescenta outra concepção alternativa, que só há interações entre compostos que formam uma mistura homogênea, sendo que na mistura heterogênea não há interações entre os componentes que a compõe.

É perceptível a dificuldade em relação à compreensão de que existem espécies químicas interagindo, sejam interações mais fracas ou mais fortes, mas existem. Rodrigues et al. (2011) discutem também, como sendo um obstáculo na compreensão das interações intermoleculares no Ensino Superior, o fato dos alunos entrarem em contato com os diversos tipos de interpretações dessas interações, tanto em sala de aula, como em livros didáticos, sem necessariamente relacioná-las, passando assim a ter problemas para identificá-las ou diferenciá-las, talvez pelas diversas nomenclaturas trabalhadas nas variadas fontes bibliográficas. 
Sendo assim, no que se refere as transições entre os níveis de diversos contextos químicos, é importante refletir e pensar em instrumentos que auxiliem na compreensão dos conceitos e também relacionar as diversas visualizações, principalmente aquelas que necessitam de um apelo visual em nível submicro, como as interações intermoleculares entre compostos.

\section{Metavisualização como estratégia de compreensão no Ensino de Química}

Uma das possíveis formas de ajudar nas dificuldades relatadas em relação aos níveis representacionais e às interações intermoleculares é a metavisualização, que é um ramo específico da metacognição (Locatelli \& Arroio, 2011).

A metacognição pode ser entendida como o monitoramento ativo e consequente regulação dos processos cognitivos (Flavell, 1976). Já a metavisualização refere-se ao pensar sobre as visualizações. Para verificar o pensamento sobre representações internas e externas, é necessário que haja uma habilidade desenvolvida em torno das visualizações (Locatelli \& Arroio, 2011), que tem seu suporte em outras habilidades, como monitorar, integrar e extrapolar, requerendo a metacognição como um processo amplo (Gilbert, 2008).

Pode-se considerar, basicamente, duas formas de visualização, a interna e a externa (Gobert, 2005; Rapp \& Kurb, 2008). Locatelli e Arroio (2011) propõem que as visualizações externas podem ser entendidas como aquelas disponíveis no ambiente, sendo muitas vezes representações desenvolvidas no âmbito educacional, como mapas e gráficos, enquanto as visualizações internas são desenvolvidas na mente e imaginação do aluno. Cada pessoa compreende, interpreta e desenvolve o conhecimento de formas distintas, portanto a imagem resultante dessa interação, que está sendo criada na mente do aluno, gerando processos cognitivos pode ser considerada como visualização interna (Locatelli \& Arroio, 2011). Vale ressaltar que perpassando por esse contexto, há também a habilidade espacial, que compreende o âmbito visuoespacial de informações que demandem representações, como ferramenta para auxílio referente à criação de visualizações significativas (Teruya et al., 2013).

Uma das diferenças entre a metavisualização e metacognição se sustenta na ideia de que, enquanto a primeira se apoia especificamente na visualização de imagens e os processos ali envolvidos, a segunda se refere a pensar sobre qualquer processo cognitivo, incluindo a visualização e outras habilidades que se suplementam (Locatelli \& Arroio, 2011). Ainda de acordo com esses autores, a visualização passa, então, a ser relevante para o processo da compreensão dos fenômenos químicos, dado que auxilia nas dificuldades em se relacionar o submicro e o simbólico, por exemplo, sendo importante que aluno desenvolva essa habilidade metavisual, tornando-se fundamental na construção do seu conhecimento.

De acordo com os aspectos levantados, a química pode ser descrita com base em modelos, fórmulas estruturais, gráficos e equações, que representam os conceitos 
e observações compreendidos pelos químicos em geral, sendo que a construção de imagens está diretamente ligada à essas descrições (Roque \& Silva, 2008).

Mesmo que as representações visuais passem a fornecer um meio de tornar conceitos abstratos mais concretos, fatores como a habilidade do professor em explicar conceitos abstratos e o aluno em desenvolver a habilidade de compreender tais explicações, ainda fazem com que o Ensino de Química não seja de simples entendimento. Além disso, a química enfatiza o verbal em detrimento do visual, sendo que as representações acabam, constantemente, ficando em segundo plano (Teruya et al., 2013).

Considerado um contexto de alunos de Ensino Médio na temática de equilíbrio químico, Gilbert, Justi e Queiroz (2009) apontam para a necessidade de que os alunos se tornem metavisuais com relação às suas representações internas. Neste sentido, recomendam atividades que envolvam modelagem, ressaltando que isso não tem sido explorado nas pesquisas da área. Como uma das conclusões, ponderam a importância de se trabalhar com modelos, bem como possibilitar ao aluno construir novas representações.

Ainda neste contexto, Wu e Shah (2004) discutem sobre a correlação entre o aprendizado de química e o desenvolvimento de habilidades espaciais. Resultados satisfatórios foram obtidos nesse aspecto, em que muitos dos erros conceituais apresentados pelos alunos foram, basicamente, devido à falta de entendimento das representações visuais.

Assim Pauletti, Rosa e Catelli (2014), em um estudo acerca dos níveis representacionais, sinalizam como importante conduzir atividades e propostas didáticas, com estratégias que coloquem os níveis em evidência, para que "esse ensino explore de forma concomitante a livre transição entre esses universos representacionais" (Pauletti et al., 2014, p. 125).

Com base nessas considerações, podemos assumir a metavisualização como relevante para a compreensão da química, bem como da ciência como um todo. Elaborar propostas de aulas e instrumentos que desenvolvam os aspectos referentes ao "pensar sobre o pensamento" e principalmente a relação disso com a visualização, no sentido de refletir sobre a elaboração de modelos, pode gerar uma autonomia em relação à aprendizagem do aluno, fazendo-o se autorregular constantemente de forma significativa.

\section{Desdobramentos da Metacognição no Ensino de Ciências}

As investigações no campo de ensino e aprendizagem tiveram foco em capacidades cognitivas e fatores motivacionais e afetivos, como determinantes principais da realização escolar (Ribeiro, 2003). A preocupação com as concepções que esses alunos traziam para a escola do mundo externo e o desenvolvimento de sua autonomia, como um ser pensante e protagonista de seu próprio conhecimento, geraram diversos estudos no campo educacional e com isso a metacognição passou a ter certo destaque. Inicialmente, as pesquisas traziam aplicações relacionadas a memória, concentração, interpretação de 
texto e leitura, mas a sua associação com a aprendizagem gerou uma aproximação entre a psicologia e a educação, de forma que passou a ser estudada também em âmbito de ensino (Brown, 1978; Flavell, 1976, 1979).

Investigar metacognição no Ensino de Ciências é procurar entender quais fatores influenciam na aprendizagem, por exemplo, em como se pensa para gerar autonomia frente aos conhecimentos, criando argumentos alusivos às discussões ou questionamentos perante a certas situações. No Ensino de Química, por exemplo, "ter consciência e controle dos próprios pensamentos é importante para desenvolver a compreensão de conceitos, mostrando um impacto significante no sucesso em solução de problemas" (Rickey \& Stacy, 2000, p. 915, tradução nossa).

Existem diversas metodologias que podem auxiliar no desenvolvimento de habilidades que trabalhem a compreensão de conceitos de forma significativa e a metacognição em sala de aula é uma forma satisfatória de fazer com que os alunos, se tornem mais conscientes de suas próprias ideias. Dentre as diversas estratégias, o prever-observar-explicar (POE) (Rickey \& Stacy, 2000) é bem relevante, nele:

[...] os estudantes fazem predições sobre um evento e explicam as razões para essas predições; isso traz à tona suas ideias iniciais. Então, eles observam uma demonstração ou conduzem um experimento no laboratório e são requisitados a reconciliarem suas observações com suas predições; a intenção é que os estudantes pensem sobre o fenômeno estudado e os faça reexaminar suas ideias iniciais (p. 918, tradução nossa).

Essa estratégia se torna interessante, pois o aluno se torna protagonista, uma vez que trabalha ativamente a cognição dele, fazendo-o participativo em todos os processos e, principalmente, sendo autônomo sobre a sua forma de pensar. Locatelli e Arroio (2014) sugerem e trazem uma modificação no método POE com a inclusão de mais duas etapas metacognitivas com o objetivo de possibilitar, ainda mais, a autorregulação do processo, sendo elas o repensar e o reexplicar (POE-RR). Além das etapas já citadas, com o acréscimo do repensar e do reexplicar, o aluno repensa constantemente suas ideias, considerando ou não outros aspectos, questionando-se sobre os modelos elaborados, explicando-os novamente. $\mathrm{Na}$ etapa de repensar, é dado ao aluno uma figura, por exemplo, para comparar com o que ele propôs e a partir disso, ele passa a redesenhar novamente suas ideias, repensando-as e reexplicando-as. Por exemplo, ao comparar os desenhos, ele percebe que não representou as interações entre moléculas da mesma substância (está repensando) e exterioriza isso dizendo que faltaram as interações entre as moléculas e que isso é importante para mantê-las próximas (está reexplicando). Para a atividade proposta para a pesquisa utilizamos os princípios da estratégia descrita, a POE-RR. 


\section{Contexto e participantes da pesquisa}

Os sujeitos da pesquisa foram graduandos de uma universidade pública paulista, matriculados na disciplina de Práticas de Ensino de Química II (PEQ II), de setembro a dezembro de 2018. Essa disciplina é obrigatória para os que cursam a Licenciatura em Química, porém optativa para os demais cursos da universidade, com carga horária de 36 horas, correspondendo a 3 aulas por semana, em regime quadrimestral.

É importante ressaltar o contexto da universidade em que essa disciplina é ofertada. Por ser uma universidade inovadora e interdisciplinar, os alunos da graduação possuem liberdade e mobilidade em relação a estruturação e montagem de sua grade curricular, podendo matricular-se em qualquer disciplina oferecida, independente do curso ao qual está vinculado e de seu tempo na universidade. Sendo assim, a turma era composta por alunos com diferentes objetivos formativos e em tempos diversos da graduação.

A quantidade de alunos envolvidos nesta pesquisa dependeu, principalmente, da disponibilidade em participar voluntariamente. Assim, para as análises realizadas neste artigo, dos 7 grupos de alunos (16 alunos no total) que se voluntariaram para a pesquisa entregando os produtos finais para análise, foi escolhido apenas um grupo de três alunos (A1, A2 e A3), tendo como justificativa a composição do grupo, que continha um integrante que estava começando o curso de licenciatura e outros que já estavam mais avançados em relação ao tempo de graduação. Além disso, é importante ressaltar para uma melhor compreensão da análise realizada, que os alunos A1 e A3 estavam avançados no curso, sendo mais experientes devido às suas trajetórias, possibilitando ter um melhor desenvolvimento nas competências requeridas, diferentemente do aluno A2, que estava no início do curso, sendo então menos experiente em comparação com os outros alunos. Durante a execução do projeto foram considerados os princípios éticos da pesquisa envolvendo seres humanos, conforme a resolução no 196/1996 do Conselho Nacional de Saúde (CNS). Para tal, no início da disciplina, todos os participantes foram informados sobre os objetivos e procedimentos metodológicos envolvidos durante sua participação, deixando claro que as atividades são parte integrante de uma pesquisa e, aqueles que manifestassem vontade para contribuir com os dados e permitissem o uso dos registros, assinariam o Termo de Consentimento Livre e Esclarecido (TCLE) e o Termo de Consentimento de Uso de Imagem (TCUI). O desenvolvimento da pesquisa foi aprovado pelo comitê de ética da referida universidade.

\section{Descrição da ação e metodologia}

A atividade proposta, na perspectiva POE-RR, foi constituída de duas partes A e $\mathrm{B}$ e tinha por objetivo explorar as visualizações dos alunos quanto às interações entre compostos e o acesso aos níveis representacionais. Para isso foram utilizados modelos explicativos para a compreensão da solubilidade entre as substâncias, utilizando-se uma estratégia metavisual, em que desenhos e modelos foram criados para que tentassem, 
com base em suas visualizações e concepções, resolver as tarefas propostas.

$\mathrm{Na}$ atividade (parte A) da ação proposta, a turma foi disposta em duplas ou trios, e a estes grupos foi perguntado "O que acontece ao se misturar água $\left(\mathrm{H}_{2} \mathrm{O}\right)$ e o líquido tetracloreto de carbono $\left(\mathrm{CCl}_{4}\right)$ ?". Eles então discutiram e pensaram em possíveis respostas para a pergunta proposta, levantando suas concepções prévias sobre o assunto. Em seguida, uma imagem do experimento envolvendo a mistura dos dois compostos foi apresentada em um projetor (Figura 1), seguida da proposta a eles, de elaboração de uma explicação do experimento observado por meio de um desenho.

Figura 1. Imagem do experimento entre água e tetracloreto de carbono

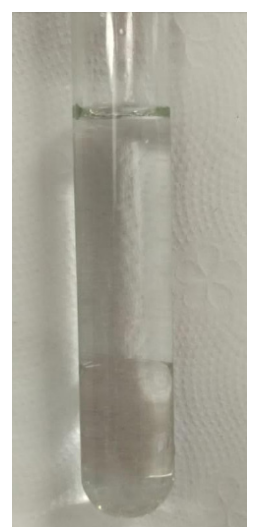

Decorrido certo tempo, apresentou-se uma possibilidade de explicação com um desenho feito pela professora (Figura 2), para que eles comparassem e discutissem as semelhanças e diferenças dos desenhos realizados por eles e o apresentado - etapa metavisual 1.

Figura 2. Possibilidade de modelo explicativo para a primeira atividade (parte A) apresentada pela docente. O traçado mais forte representa as interações do tipo ligação de hidrogênio e o tracejado mais fraco as interações do tipo dipolo induzido
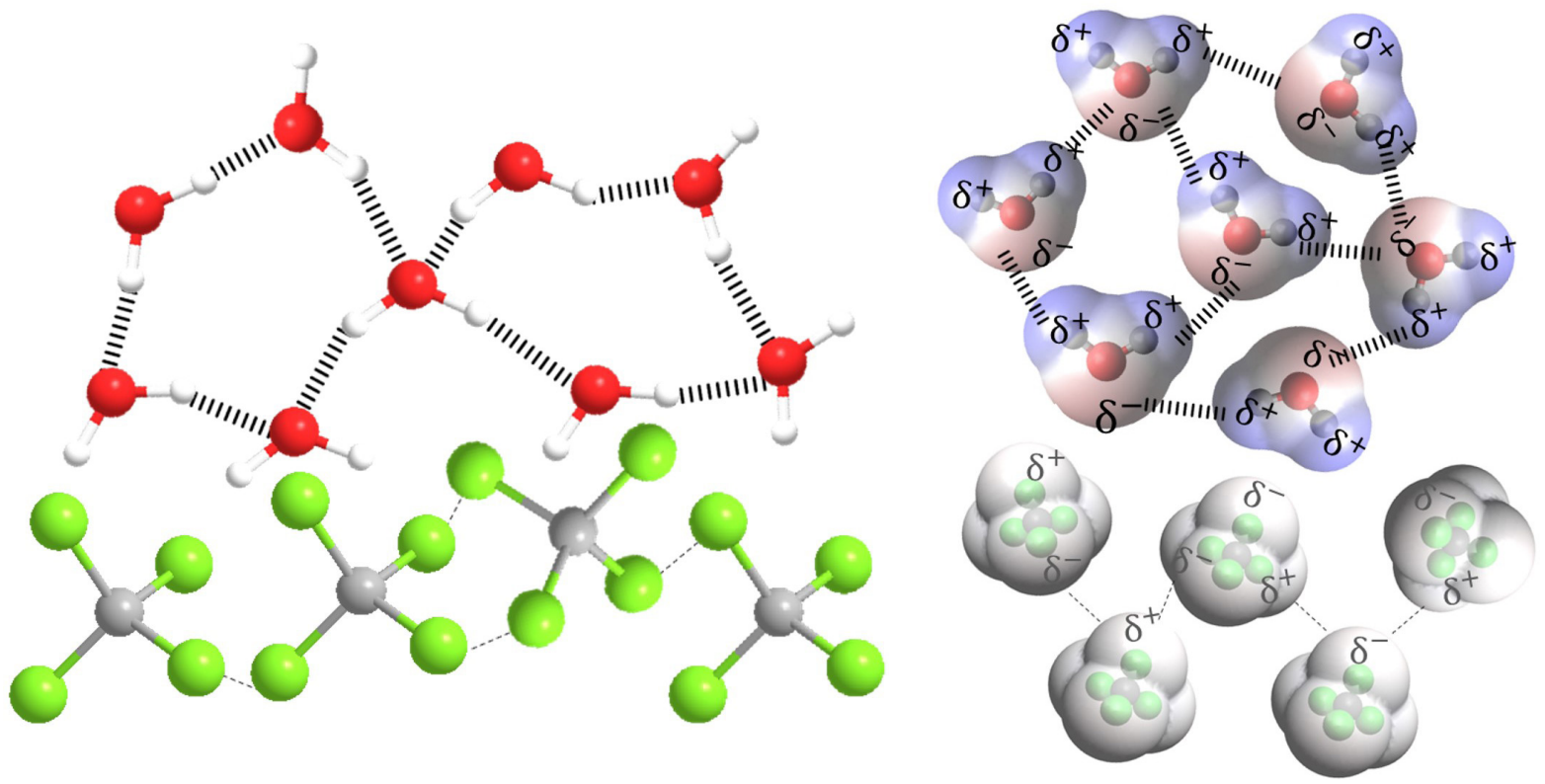
Assim, a docente da turma promoveu uma discussão coletiva e de sistematização das ideias. O objetivo foi de que os alunos pudessem construir/reconstruir conceitos relacionados à geometria e polaridade das moléculas (submicro) e relacionassem isso às propriedades das substâncias, como a solubilidade (macro). Esperava-se como resposta que os alunos conseguissem chegar em uma mistura heterogênea, em que os dois compostos não iriam se solubilizar devido às diferentes interações que os compostos fazem entre si, representando assim a água na parte superior e o tetracloreto de carbono na parte inferior. Além disso, nas explicações dos modelos, esperava-se que eles levantassem aspectos como, por exemplo, polaridade, geometria e eletronegatividade para discutir sobre as interações ali existentes.

Na parte B da atividade, fez-se uma nova pergunta: "O que acontece ao se adicionar iodo sólido $\left(\mathrm{I}_{2}\right)$ à mistura anterior, de água $\left(\mathrm{H}_{2} \mathrm{O}\right)$ e tetracloreto de carbono $\left(\mathrm{CCl}_{4}\right)$ ?". A mesma metodologia utilizada anteriormente foi seguida, realizando a discussão para levantamento das concepções prévias e apresentando a imagem do experimento realizado (Figura 3), seguida da proposta de elaboração de uma explicação por meio de um desenho e da seguinte pergunta: "A água constitui a fase inferior ou superior? Por quê?". Esperava-se como resposta que os alunos conseguissem chegar em uma mistura heterogênea, assim como na Parte A, porém eles deveriam discutir sobre a interação do iodo com o tetracloreto de carbono e a sua solubilização neste solvente, discutindo aspectos no nível submicro, principalmente sobre a polaridade entre as moléculas.

Figura 3. Imagem do experimento entre água, tetracloreto de carbono e iodo sólido

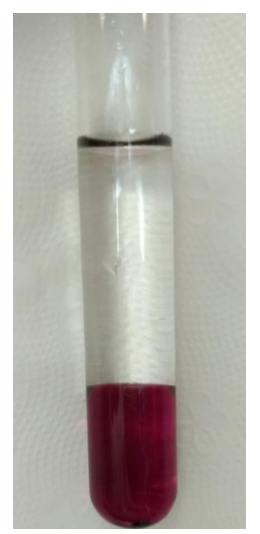

Após o tempo de elaboração do desenho, apresentou-se nova possibilidade elaborada pela professora (Figura 4), para que eles comparassem e discutissem as semelhanças e diferenças entre os desenhos realizados por eles e o apresentado - etapa metavisual 2 . 
Figura 4. Possibilidade de modelo explicativo para a segunda atividade (parte B) apresentada pela docente. O traçado mais forte representa as interações do tipo ligação de hidrogênio e o tracejado mais fraco as interações do tipo dipolo induzido
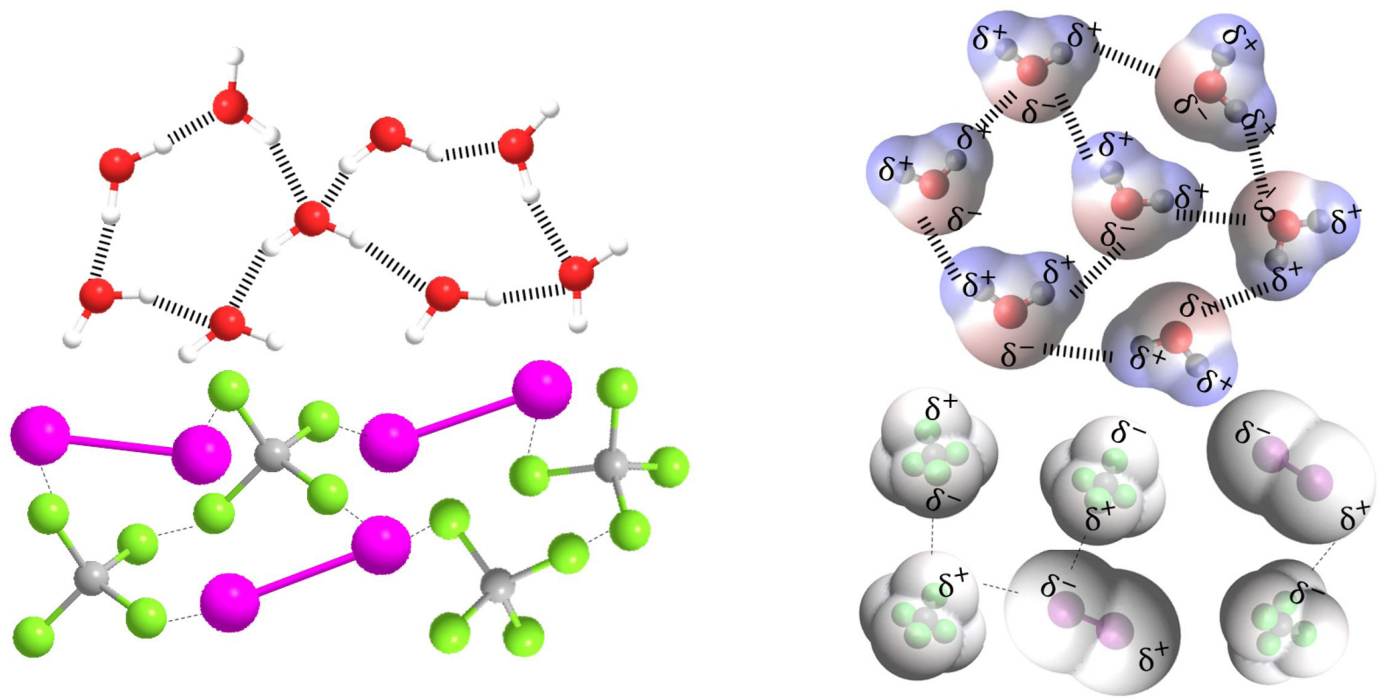

Assim, foi feita pela docente da turma uma nova discussão coletiva e de sistematização das ideias. A Figura 5 ilustra as etapas da metodologia realizada.

Figura 5. Esquema das etapas metodológicas

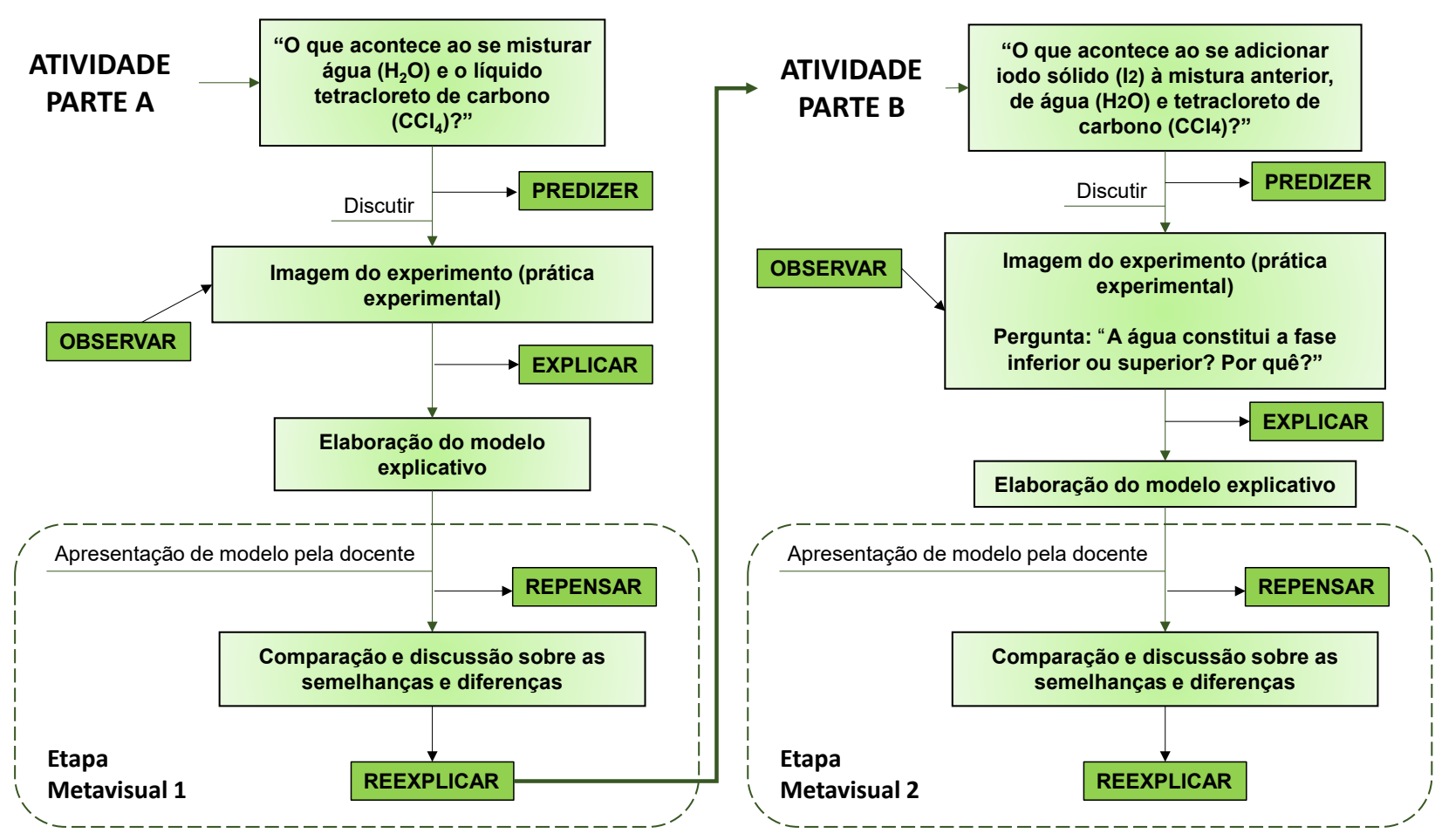


Como instrumentos de coleta de dados, procurou-se por formas que permitissem verificar as visualizações apresentadas pelos alunos em relação aos processos químicos no nível submicro. Para isso, todo o processo foi documentado com base em gravações audiovisuais, contemplando a técnica "think aloud" (Block \& Israel, 2004), para a captação da conversa do grupo e do processo como um todo, para que fosse possível analisar como os alunos concebem a atividade, as possíveis dificuldades e questionamentos encontrados. Essa orientação foi disponibilizada aos discentes e os diversos registros realizados por eles foram fotografados para documentação, sendo importante na comparação com os instrumentos audiovisuais.

$\mathrm{Na}$ organização dos dados, todas as documentações feitas foram registradas e transcritas, sendo analisadas relações entre as falas e as fotografias dos produtos feitos pelos alunos. Esses materiais, foram lidos diversas vezes para se tentar identificar pontos em comum (Bogdan \& Biklen, 1994), elaborando categorias para análise. Para isso, utilizou-se a técnica de análise de conteúdo de Bardin (2011), considerada um método de organização e análise de dados. Porém, dado que as transcrições apresentavam um contexto particular, não foi suficiente uma análise apenas do conteúdo, sendo também necessária uma análise textual discursiva com base em Moraes (2003). Nessa análise, a transcrição foi separada em diversos trechos, levando-se em consideração os contextos específicos. Os trechos foram lidos diversas vezes e, com base nisso, categorias e subcategorias foram criadas para classificá-los, gerando assim, novos resultados que poderiam ser interpretados de forma a gerar um significado relevante para o ensinoaprendizagem de química.

\section{Resultados e análises}

Nas análises a seguir, foram elaboradas categorias baseadas nas transcrições dos áudios gravados pelos alunos, na feitura das tarefas propostas pela docente responsável. Para a criação das categorias, fez-se uma análise minuciosa das transcrições obtidas, procurando-se por semelhanças e padrões entre elas. Na figura 6 são apresentadas as categorias elaboradas na organização dos dados obtidos e suas descrições, para se identificar e analisar como foi o acesso aos níveis representacionais pelos alunos:

Para a categoria 1, "Nível Macro", foram analisados trechos que apresentaram características referentes ao nível macro. Dentro dessa categoria, foram elaboradas duas subcategorias,dadoo contexto queastranscriçõesobtidasapresentavam, ou seja, umaúnica categoria para o nível macro seria insuficiente para explanar todos os aspectos envolvidos nas transcrições. Assim temos, a subcategoria "1.1. Somente Macro", que se refere aos trechos no qual o aluno propõe explicações utilizando somente aspectos macroscópicos. 
Figura 6. Categorias elaboradas para análise com base nas transcrições

\begin{tabular}{|c|c|c|}
\hline Categoria & Subcategoria & Descritor (Definiçãa) \\
\hline \multirow{2}{*}{$\begin{array}{l}\text { 1. Nível } \\
\text { Macro }\end{array}$} & $\begin{array}{l}\text { 1.1. Somente } \\
\text { Macro. }\end{array}$ & $\begin{array}{l}\text { O aluno propõe e explica o contexto exposto utilizando somente } \\
\text { aspectos macroscópicos. }\end{array}$ \\
\hline & $\begin{array}{l}\text { 1.2. Macro } \\
\text { suportando o } \\
\text { Submicro. }\end{array}$ & $\begin{array}{l}\text { O aluno utiliza os aspectos visíveis referentes ao nível macroscópico } \\
\text { para validar as hipóteses e modelos explicativos em nível submicro. }\end{array}$ \\
\hline \multirow[b]{2}{*}{$\begin{array}{l}\text { 2. Nível } \\
\text { Submicro }\end{array}$} & $\begin{array}{l}\text { 2.1. Somente } \\
\text { Submicro. }\end{array}$ & O aluno utiliza de conceitos e palavras que remetem ao nível submicro. \\
\hline & $\begin{array}{l}\text { 2.2. Submicro } \\
\text { explicando o } \\
\text { Macro. }\end{array}$ & $\begin{array}{l}\text { O aluno utiliza modelos explicativos em nível submicro para validar os } \\
\text { fenômenos vistos no nível macroscópico. }\end{array}$ \\
\hline $\begin{array}{l}\text { 3. Nível } \\
\text { Simbólico }\end{array}$ & $\begin{array}{l}\text { 3.1. Simbólico } \\
\text { suportando o } \\
\text { submicro }\end{array}$ & $\begin{array}{l}\text { O aluno utiliza recursos do nível simbólico para representar os modelos } \\
\text { em nível submicro. }\end{array}$ \\
\hline
\end{tabular}

O trecho a seguir, que utiliza aspectos visuais (macro) como fases e interface para chegar a uma conclusão, exemplifica e reforça a descrição da categoria $1.1^{1}$ : A3: Bom, o de baixo, como tínhamos falado antes de gravar e falando de novo, é porque ele é menos denso...

A2: Ele é mais denso.

A3: Ele é mais denso, desculpa, o tetracloreto de metano ${ }^{2}$.

A1: Então nós fizemos uma representação macro demonstrando as duas fases e a interface entre a água e o... tetraclorometano, sendo que o tetraclorometano era mais denso.

A3: Isso.

A1: Por isso a posição dele abaixo.

A3: Isso.

Neste trecho, os alunos utilizaram aspectos macroscópicos, como a formação de fases, para prever o que aconteceria ao misturar a água e o tetracloreto. É válido ressaltar, que os aspectos visuais fenomenológicos, como a formação de interface, os auxiliaram a explicar se haveria uma mistura homogênea ou heterogênea, além da posição ocupada por cada líquido na mistura.

1 Nas transcrições, podem existir erros conceituais perante a explicação da situação problema proposta na atividade, porém analisou-se apenas o acesso aos níveis representacionais e não os erros conceituais.

2 O correto é tetracloreto de carbono 
Já a categoria "1.2. Macro suportando o Submicro", se refere aos trechos nos quais se utiliza os aspectos visíveis e sensoriais referentes ao nível macroscópico, para validar as hipóteses e modelos explicativos em nível submicro propostos. Vale ressaltar que essa subcategoria trata de uma transição que acontece do nível macro seguindo para o nível submicro, necessariamente neste sentido. $\mathrm{O}$ trecho a seguir, exemplifica e reforça a descrição da categoria 1.2:

A2: Vai interagir. Com o tetracloreto de carbono, pela polaridade...

A3: Vamos lá. Iodo sólido... Agora acho que vai ficar homogêneo. Tudo. Porque o iodo vai interagir, o iodo apolar, vai interagir com a molécula com o tetracloreto e, nisso que ele interagir, vai conseguir interagir com a água também, porque querendo ou não, ele vai conseguir ionizar ${ }^{3}$ dependendo...

Neste trecho, foram utilizados aspectos macroscópicos, como o estado físico do iodo e o aspecto visual da mistura, para validar um modelo explicativo no nível submicro, como as possíveis interações e polaridades entre as moléculas.

Para a categoria 2, "Nível Submicro", foram analisados trechos que apresentaram características referentes ao nível submicro. Dentro desta categoria foram elaboradas duas subcategorias, posto que as criações novamente se fizeram necessárias, dado o contexto que as transcrições obtidas apresentavam, ou seja, uma categoria seria insuficiente para explanar todos os aspectos envolvidos nas transcrições. A subcategoria "2.1. Somente Submicro", se refere aos trechos no qual o aluno utilizou de conceitos e palavras que remetem ao nível submicro, somente, sem fazer referências ao nível macroscópico. O trecho a seguir, exemplifica e reforça a descrição da subcategoria 2.1:

A1: O tetraclorocarbono tem 4 ligações possíveis e o cloro vai se disponibilizar (organizar) geometricamente em volta do carbono, então ele deve ser... Apolar, correto?

A3: Uhum.

A1: A água sendo polar ela vai se dispor ao redor do cloro...

A2: Do mesmo jeito.

A1: Da mesma forma. Não dissolve..., mas o tetracloreto de carbono não tem polarizabilidade?

A2: Não sei o que é isso.

A1: É um conceito de química que você pode perturbar a polaridade de um determinado...

3 Embora o aluno diga que o iodo irá "ionizar", o correto é que ele irá interagir com o tetracloreto de carbono pela semelhança de polaridade (ambos são apolares). 
Neste trecho, os alunos lançaram mão de conceitos relacionados somente ao nível submicro para prever e explicar a tarefa proposta, como ligações químicas e polaridade.

Já a categoria "2.2. Submicro explicando o Macro", se refere aos trechos nos quais modelos explicativos são utilizados em nível submicro para validar os fenômenos vistos no nível macroscópico. O trecho a seguir, exemplifica e reforça a descrição da categoria 2.2:

A1: Se ele vai solvatar, minimamente, eu vou ter moléculas de um na fase do outro, isso necessariamente vai causar uma turbidez?

A3: Então, depende da quantidade que vai...

A1: Os dois são miscíveis...

A3: São im..?

A1: Imiscíveis.

A3: Então, eu acredito que tem uma quantidade muito mínima que...

A1: A gente tem a capacidade de observar, por exemplo, um átomo, uma molécula, no meio?

A3: Não uma molécula não, por isso que eu "tô" falando que se... A quantidade tem que ser uma coisa assim de analítico mesmo.

Neste trecho, os alunos utilizaram-se de conceitos em nível molecular, como solvatação de moléculas para explicar e justificar fenômenos em nível macro, como uma provável turbidez ou miscibilidade entre os compostos.

É interessante pontuar a diferença entre a subcategoria 1.2 e a 2.2. A subcategoria 1.2 sugere uma transição que perpassa por aspectos de nível macro e que dá suporte para a criação e validação de um modelo em nível submicro. Concernente à subcategoria 2.2, esta se pauta na criação de modelos explicativos com base em conceitos em nível submicro, para então explicar e justificar os fenômenos visíveis no nível macro.

Por fim na categoria 3, "Nível Simbólico", foram analisados trechos que apresentaram características referentes ao nível simbólico. A subcategoria "3.1. Simbólico suportando o Submicro", se refere aos trechos nos quais recursos do nível simbólico são utilizados para representar os modelos em nível submicro. Os trechos a seguir, exemplificam e reforçam a descrição da categoria 3.1:

A1: Pode fazer assim basiquinho. Coloca aqui “O”... A gente pode colocar também, isso daqui, com um mínimo de ordenação.

A2: Achei que você ia colocar só o símbolo?

A2: Só eu que acho que fazer com o símbolo é mais fácil que ficar fazendo com bolinha? 
A1: Pode ser. Fazer pequenininho aqui.

Neste trecho, A1 e A2 discutiram sobre como representar as moléculas, no caso por símbolo ou por "bolinha", perpassando assim, pela transição do nível simbólico e submicro, para explicar as possíveis interações ali presentes.

A Figura 7 resume e apresenta as subcategorias referentes às transições e suas respectivas direções (Subcategorias 1.2, 2.2 e 3.1), expondo também as subcategorias referentes ao acesso único de um nível, sem necessariamente haver uma transição entre níveis representacionais distintos (Subcategorias 1.1 e 2.1).

Figura 7. Categorias criadas e seus diversos acessos e transições. Os sentidos das setas indicam a direção em que o ocorre a transição entre os níveis representacionais

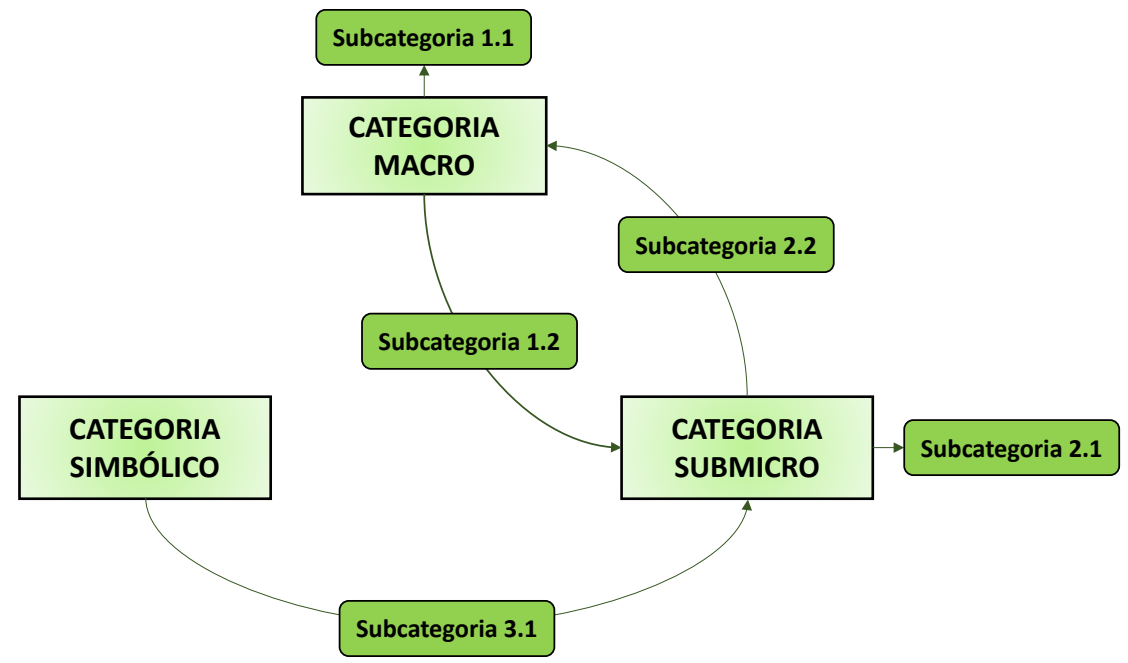

Com base nos resultados, elencou-se para cada trecho analisado, uma das três categorias e subcategorias referente (figura 7), para uma análise mais efetiva sobre quais são os níveis e transições que os alunos mais acessaram para elaborar modelos explicativos envolvendo situações químicas. A Tabela 1 reúne as informações obtidas, expressando o panorama geral quanto aos conceitos investigados.

Tabela 1. Dados organizados segundo as falas e trechos da transcrição e as categorias e subcategorias correspondentes

\begin{tabular}{lllc}
\hline Categoria & Subcategoria & Total de Trechos & Subtotal \\
\hline \multirow{2}{*}{ 1. Nível Macro } & 1.1. Somente Macro. & 4 & 7 \\
\cline { 2 - 3 } & 1.2. Macro suportando o Submicro & 3 & \multirow{2}{*}{16} \\
\hline \multirow{2}{*}{ 2. Nível Submicro } & 2.1. Somente Submicro. & 8 & 5 \\
\cline { 2 - 3 } & 2.2. Submicro explicando o Macro. & 8 & 5 \\
\hline 3. Nível Simbólico & 3.1. Simbólico suportando o Submicro & 5 & 28 \\
\hline Total & & & 5 \\
\hline
\end{tabular}

Pelos dados, é perceptível que os alunos acessaram, em alguma medida, todos os níveis representacionais, o que é desejável para a compreensão adequada da química e o fazem com diversas direções de transição (tabela 1). Com relação a cada nível 
acessado, dos 28 trechos analisados na transcrição, 16 se referem ao nível submicro, 7 ao nível macro e 5 ao nível simbólico, sendo assim, observa-se uma prevalência do nível submicro, o que é importante, uma vez que os modelos explicativos em química são expressos em nível submicroscópico.

É válido ressaltar, que A1 e A3 acabaram por conduzir as discussões para o nível submicro com mais frequência. Isso pode ser observado nas falas expostas ao longo da discussão, em que as dificuldades e considerações de A2 permeiam, basicamente, os aspectos visíveis. Isso torna perceptível que A1 e A3 passam a problematizar e discutir os fenômenos apresentados, levando em consideração os aspectos relacionados em nível submicro. Na fala a seguir, exemplifica-se essa condição de A1 e A3 com relação ao nível submicro.

A1: Mas eles também representaram as cargas parciais e isso a gente não colocou.

A3: Mas assim, são dois ali, um com cargas parciais o outro...

A2: Mas você meio que relatou isso daí fazendo a ligação de hidrogênio na água.

A3: Sim é porque ficou implícito. Mas tá aqui, sempre direcionado, você só não...

A2: Pensou um pouco nas cargas.

No trecho apresentado, os alunos discutem sobre o modelo realizado por eles, apresentando as semelhanças nos aspectos submicro em relação as cargas e interações para endossar suas explicações. Ao longo dessa discussão, percebe-se que A3 complementa A1 trazendo aspectos das cargas parciais, conduzindo um raciocínio, o que é confirmado por A2, que fala sobre as ligações de hidrogênio. Contudo, A2 apenas reforça que foi uma explicação feita por A1, mostrando assim uma dependência de A2 em relação a A1 e A3 na elaboração dos modelos e discussões.

Ainda com relação ao que aconteceria, quando a água $\left(\mathrm{H}_{2} \mathrm{O}\right)$ e tetracloreto de carbono $\left(\mathrm{CCl}_{4}\right)$ se misturassem, observou-se que a criação dos modelos se pautou em aspectos, prevalentemente, em nível submicro (Subcategoria 2.1). Como exemplos, temos a polaridade entre as moléculas dos compostos ou em uma transição apoiada nos aspectos em nível submicro, para prever ou explicar possíveis aspectos ao nível macro (Subcategoria 2.2). O trecho abaixo exemplifica:

A2: Reduzir (Induzir?), a polaridade você fala?

A1: Sim! Lembra daquelas interações intermoleculares? Então será que ele não pode induzir uma polaridade? Nem tudo que é polar vai dissolver tudo que é polar e nem tudo que é apolar vai dissolver tudo que é apolar...

A3: Acho que fica um sistema bifásico, acho que fica um sistema bifásico...

Neste trecho descrito, os alunos fizeram uma discussão com base na polaridade das moléculas dos compostos ao se misturarem, todavia, ressalta-se o contexto, no qual 
se pautaram em aspectos em nível submicro, para assim prever como iria se constituir o nível macro. Aspecto esse, presente nas falas da transcrição e percebido na análise ampla dos trechos, auxiliando na delimitação para a criação da categoria 2.2.

Além das transições feitas relacionando o nível submicro, as que são apoiadas no macro também são significativas. $\mathrm{Na}$ atividade referente ao que aconteceria se iodo sólido $\left(\mathrm{I}_{2}\right)$ fosse adicionado à mistura anterior, de água $\left(\mathrm{H}_{2} \mathrm{O}\right)$ e tetracloreto de carbono $\left(\mathrm{CCl}_{4}\right)$, foi utilizado o nível macro em alguns momentos. Contudo, não somente em relação aos aspectos visuais que eles poderiam prever, mas também para justificar e validar seus modelos no nível submicro. As falas nos trechos a seguir, discutem o aspecto referente a categoria 1.2 .

A1: Vai mudar de cor.

A2: Você sabe o que vai formar? Na Interação do iodo com o tetra?

A3: Eu não sei o que vai formar...

A1: Eu não sei se eles reagem.

A3: Não reagir... isso que eu tô falando. Vai interagir tipo, por exemplo... Ele tá sólido lá né?

A1: O Cloro é mais eletronegativo que o iodo, então é difícil ele sair de uma ligação com o carbono para ter uma alteração com o iodo... ele pode diluir.

A3: Ele vai diluir ${ }^{4}$ o iodo e aí ele pode interagir com a água, porque o iodo sólido ele não dilui e não interage com a água, o iodo, $\mathrm{I}_{2}$, ele não faz nada com a água. Mas acho que ele, em contato com o tetracloreto, vai conseguir ter contato com a água, o sistema todinho vai interagir.

Na discussão, o aspecto macroscópico do iodo passou a ser utilizado, no caso, um sólido, para tentar criar um modelo explicativo em nível submicro e validá-lo com base no panorama exposto.

Relevante ainda, é a forma como esses alunos repensaram o nível macro. A transição entre o nível macro e o submicro, mesmo que acessada poucas vezes, mostra um domínio deles em relação ao entendimento dos fenômenos que poderiam estar acontecendo, o mesmo vale para as transições do sentido do nível submicro para o macro, indicando, que por mais que haja dificuldades de abstração e concretude entre os níveis, há possibilidades de uma transição bem-sucedida e expressiva para a criação de modelos.

Ainda no trecho destacado é interessante ressaltar o aspecto das interações intermoleculares citadas por A1. Francisco Junior (2008) discute sobre as concepções de interações intermoleculares e, segundo pesquisas, muitos acreditam que só há

4 Embora o aluno tenha utilizado o termo "diluir", neste caso o correto é dissolver. 
interações entre compostos que formam uma mistura homogênea, sendo que na mistura heterogênea não haveria interações entre os compostos. Na parte de repensar a atividade e comparar com o modelo apresentado pela docente responsável da disciplina, é possível perceber que eles tinham noção das interações entre os compostos de cada fase e quais seriam essas interações, conforme pode ser observado nas falas:

A1: Mas nós não pensamos em um ordenamento certo para o "tetracloro". Enquanto a água segue uma ordem mesmo que dinâmica...

A3: Mas até a interação entre o tetracloro ela é fraca, porque é aquela interação/ força de London, por ser já tudo apolar mesmo...

Em relação a subcategoria 3, observou-se certa dificuldade na compreensão dos símbolos químicos, que pode ser exemplificado nas falas dos trechos abaixo, quando estavam tentando desenhar um possível modelo para explicar a tarefa pedida.

A2: Só que eu acho que fazer com o símbolo é mais fácil que ficar fazendo com bolinha?

A2: Mas você está misturando os dois! Ou um ou outro.

A1: Sorry! E o "Cl” tem que ser separado.

A2: Esse negócio separado não sabia não.

A1: Eu acho que vou lembrar desse negócio do cloro ser dividido pra sempre porque agora "tá" sendo um obstáculo!

A2: Dessa eu não sabia não.

A utilização de símbolos, sobretudo para A2, se tornou um obstáculo representacional importante, trazendo dificuldades na forma dele se expressar e representar o modelo explicativo.

Outro ponto importante a ser assinalado é a forma como o processo da atividade ocorreu, para se conseguir acessar os níveis utilizados pelos alunos.

Como último ponto de análise, vamos ilustrar a importância do processo reflexivo metavisual na etapa do repensar e reexplicar, em que analisamos um trecho do momento em que comparam os modelos feitos por eles (Figura 8) e os apresentados pela professora (Figuras 2 e 4). 
Figura 8. Desenhos apresentados pelos alunos perante a tarefa de prever (Parte A e B)

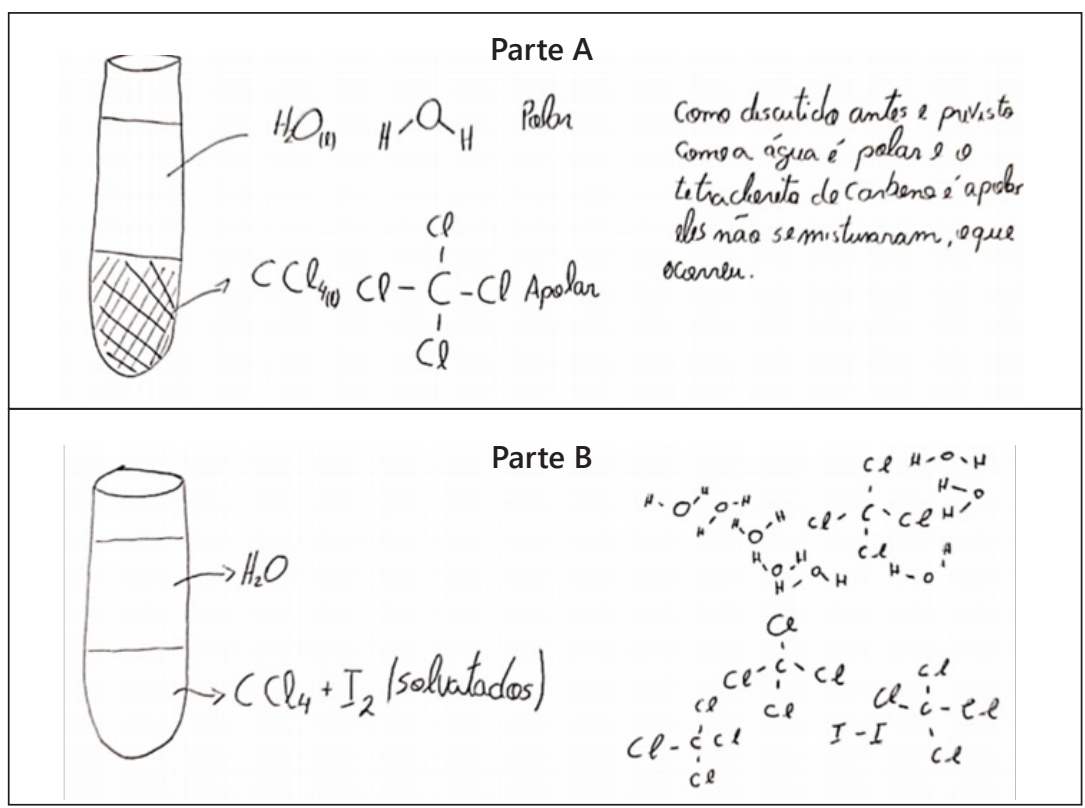

As falas abaixo, A1 e A3 refletem acerca dessa comparação de modelos:

A1: Analisando (referindo-se a parte B, Figura 8), ficaram novamente parecidos (comparando com a Figura 4). A única diferença é que a gente considerou uma dissolução mínima entre as fases, mesmo que a gente não tenha desenhado uma molécula de água de baixo agora, mas porque esquecemos.

A3: Ah não, porque tecnicamente, já englobei daqui de cima, porque no outro gabarito (Figura 2) não tinha que nem aqui. Aqui nem cogitei, é só do iodo.

A1: Mas nós colocamos aqui o cloreto, tetraclorometano.

A3: Ah... mas tá bom, tá ótimo.

A1: Representamos de forma coerente de como foi passado.

No momento de repensar e discutir, eles conseguem uma autonomia para elencar o que conseguiram fazer e o que faltou, e o porquê de eles terem feito o modelo daquela forma, como pode ser observado quando A1 afirma que "ficaram novamente parecidos". Ele ainda, para justificar a afirmativa, discute que consideraram uma certa "dissolução" entre as fases, diferente do modelo apresentado pela docente, ressaltando aqui a autonomia em confrontar o modelo proposto. Por fim, reforçando ainda o repensar na discussão, A3 discute que englobou as moléculas, fortalecendo sua afirmação com "porque no outro gabarito não tinha que nem aqui", no qual apresenta argumentos que sugerem que aspectos da primeira atividade foram mobilizados para compor a segunda tarefa proposta. Por fim, reforçam seu modelo com a afirmativa da fala de A1, que diz que o modelo foi representado de forma coerente. 
Um aspecto perceptível ao longo da discussão feita, é que não basta que haja apenas acesso aos níveis representacionais, mas sim, que haja uma transição entre esses níveis e que essas transições possam auxiliar o aluno a desenvolver um entendimento consistente no contexto do Ensino de Química.

Além do mais, tentar analisar uma possível qualidade desses acessos e transições, seja no nível ou entre os níveis, pode auxiliar no entendimento do motivo pelo qual o aluno apresenta as diversas dificuldades discutidas. Chin e Brown (2000), em um contexto de aula de laboratório de química, fazem comparações entre abordagens superficiais e mais profundas no processo de aprendizagem em ciência. Segundo os autores, a abordagem superficial é focada nos aspectos visíveis (macro), em contraponto com a mais profunda, em que os alunos trazem explicações mais elaboradas, descrevendo mecanismos de causa e efeitos do que estão estudando. Essas classificações e comparações podem ser um caminho a se seguir para repensar uma discussão mais profunda em relação a qualidade dessas transições.

\section{Conclusões e implicações}

Retomando o objetivo investigativo desse estudo, pautado na identificação e compreensão dos níveis representacionais acessados pelos alunos, suas dificuldades, bem como o papel da estratégia metavisual durante a elaboração de modelos explicativos, considerando-se o contexto das interações intermoleculares entre compostos, trazemos algumas considerações finais.

Primeiramente, como foi observado em pesquisas que discutem os níveis representacionais, os resultados aqui encontrados foram semelhantes em relação aos acessos ao nível macro, onde os alunos conseguiram expressar e utilizar o nível macro de forma satisfatória. Isso porque este nível é mais concreto e envolve os aspectos visuais e fenomenológicos, o que o torna mais tangível aos alunos (Chittleborough \& Treagust, 2008; Gibin \& Ferreira, 2010; Johnstone, 1993). Vale ressaltar que esse nível foi utilizado de forma também reflexiva, possibilitando transições com o nível submicro no sentido de validação de modelos, já evidenciado no trabalho de Locatelli e Arroio (2017) e AlBalushi (2013).

Outra constatação com relação ao nível, foi observar as diferentes transições e em diversas direções que os alunos demonstraram, o que é considerado uma difícil tarefa (Johnstone, 1993; Wartha et al., 2012; Santos \& Arroio, 2016, Keiner \& Graulich, 2019). Essa distinção (direções das transições) se faz necessária, já que existem certos contextos que discutem a complexidade em se transitar entre os níveis principalmente devido as diferenças de escala (Chittleborough \& Treagust, 2008). Sair de um nível que trabalha o fenomenológico, com características visíveis, e por meio disso, buscar uma explicação no nível submicro, não visível, que se baseia em modelos explicativos (distante do observável) e vice-versa, poderá auxiliar o aluno no sentido de habilidades relacionadas aos aspectos visuoespaciais e também na compreensão de diversos fenômenos, principalmente no que diz respeito a criação de modelos explicativos, como 
observado por Locatelli e Arroio (2017). Pode-se da mesma forma, pensar em sair de explicações e modelos que trabalham aspectos do submicro, como as interações entre as moléculas, para prever possíveis características fenomenológicas no macro, como a diferença de solubilidade, o que justifica a importância da categorização proposta na tabela 1, reforçando assim a pertinência de se analisar ambos os sentidos de acesso e transições realizadas.

Assim, considera-se todos os elementos, como o acesso, a transição e a direção referentes ao nível representacional (Figura 7), pois é essa combinação que vai auxiliar o aluno a desenvolver o entendimento dos fenômenos químicos apropriadamente. Isso é de relevância no contexto do Ensino de Química, colocando em evidência os níveis representacionais (Pauletti et al., 2014). Dessa forma, o modelo proposto nesta pesquisa (Figura 7) evidencia as possíveis transições existentes e que podem e devem ser ressaltadas junto aos alunos. Ainda com relação à direção do acesso, acreditamos que possa agregar na aprendizagem, com vistas à compreensão da totalidade do processo químico (Wartha et al., 2012), que pode ser alcançado na aproximação dos três níveis, discutindo as possíveis associações e direções em que ocorrem as transições e que podem favorecer a aprendizagem. Portanto, ressalta-se a importância de nosso modelo de categorização (que inclui as direções) para uma análise que considere aspectos amplos sobre as transições, desde o acesso, a forma e, principalmente, os caminhos seguidos.

Além disso, observou-se algo bem diferente do que costuma ser apontado por trabalhos anteriores, em que o nível macro seria o mais acessado (Gilbert \& Treagust, 2009; Santos \& Arroio, 2016). Ao invés disso, as transições mais prevalentes demonstradas por esses alunos foram as referentes ao nível submicro, que normalmente os alunos apresentam problemas (Chittleborough \& Treagust, 2008; Gibin \& Ferreira, 2010; Johnstone, 1993; Santos \& Arroio, 2016). Com relação ao submicro, Chittleborough e Treagust (2008) dizem que alunos acabam estabelecendo uma transição muitas vezes rasa ou nem existente, o que não observamos neste trabalho. Uma possível explicação é o tempo de curso que esses alunos apresentavam, no sentido qualitativo de experiências, sendo que os alunos A1 e A3 eram mais experientes se comparados ao A2, este último evidenciando maior dificuldade na compreensão da química (Chittleborough \& Treagust, 2008; Gomez et al.1995; Santos et al. 2017), valendo também para um maior entrave nas representações em si (Kozma \& Russel, 2005). Como o grupo era formado por dois alunos mais experientes, isso parece ter favorecido o entendimento conceitual de química, inclusive no nível submicro para o grupo como um todo.

Já em relação as dificuldades manifestadas por eles, uma delas pode ser em relação ao nível simbólico, que é complexo e exige uma demanda cognitiva para sua compreensão (Taber, 2009; Cedran et al., 2018), conforme também observado no nosso trabalho, com destaque à representação do elemento cloro no nível simbólico. Justamente por isso (demanda cognitiva), Taber (2009), Locatelli e Arroio (2017) e Flôr e Cassiani (2016) pontuam que os alunos, ao estudarem química, podem não conseguir compreender os conceitos que os símbolos carregam. Concordamos e acrescentamos 
tratar-se de uma linguagem específica a ser assimilada e compreendida, o que carece de ser, cuidadosamente, construída e retomada durante as aulas.

Com base nesse contexto da construção da linguagem química, é relevante considerar, como Flôr e Cassiani (2016) discutem, a forma como os professores trabalham as simbologias em sala de aula. Muitas vezes, o nível simbólico é trabalhado sem uma articulação com um contexto, podendo ocorrer assim certo distanciamento entre a linguagem comum e a linguagem própria do âmbito químico, reforçando ainda mais as possíveis dificuldades apresentadas pelos alunos.

Concernente à atividade metavisual utilizada, seguindo o POE-RR (Locatelli \& Arroio, 2014), temos que as etapas metavisuais foram fundamentais no processo de aprendizagem, já que os alunos puderam ter a possibilidade de autorregular suas construções, modelando seus conceitos, considerando outros aspectos que foram despercebidos anteriormente (Locatelli \& Arroio, 2017) com relação aos conceitos envolvidos nas interações intermoleculares, com oportunidade de reconstruir seus modelos mentais internos com relação ao que estavam buscando compreender. Os alunos sendo expostos a tarefas, devem mobilizar seus esquemas mentais prévios, modelando suas representações internas acerca das interações intermoleculares, trabalhando tanto as representações internas como as externas, o que vai ao encontro de Gilbert et al. (2009) com relação à importância de propiciar momentos de modelagem dos conceitos químicos.

Como uma limitação deste trabalho, levanta-se uma reflexão acerca das qualidades dessas transições. Como colocado, acessar e transitar nos níveis é relevante, entretanto, deve-se refletir sobre a qualidade com que essas transições ocorrem, podendo como hipótese ser de uma abordagem mais profunda, na qual o aluno possui um maior domínio dos conceitos e visualizações de cada nível, ou então, com uma abordagem mais superficial, transitando sem relacionar os conceitos, de forma rasa e sem argumentos, semelhante ao que afirma Chin e Brown (2000).

Finalizando, sugere-se outras investigações para que todos esses aspectos mencionados sejam mais bem elucidados, recomendando-se para trabalhos futuros um foco em investigar como que a visualização e o repensar sobre ela (metavisualização) podem estar relacionados ao processo de aprendizagem em química, inclusive considerando-se diversos contextos e conteúdos químicos distintos.

\section{Agradecimentos}

Aos discentes que, voluntariamente, participaram da pesquisa e à Fundação de Amparo à Pesquisa do Estado de São Paulo (Fapesp). 


\section{Referências}

Al-Balushi, S. M. (2013). The effect of different textual narrations on students' explanations at the submicroscopic level in chemistry. Eurasia Journal of Mathematics, Science \& Technology Education, 9(1), 3-10. https://doi.org/10.12973/eurasia.2013.911a Bardin, L. (2011). Análise de conteúdo. Edições, 70.

Block, C. C., \& Israel, S. E. (2004). The ABCs of performing highly effective think-alouds. The Reading Teacher, 58(2), 154-167. https://doi.org/10.1598/RT.58.2.4

Bogdan, R., \& Biklen, S. (1994). Características da investigação qualitativa. In Investigação qualitativa em educação: Uma introdução à teoria e aos métodos. Porto editora.

Brasil (2001). Diretrizes Curriculares Nacionais para os Cursos de Química. http:// portal.mec.gov.br/cne/arquivos/pdf/CES1303.pdf

Brown, A. L. (1978). Knowing when, where, and how to remember: A problem of metacognition. In Glaser, R. (ed) Advances in Instructional Psychology (Vol.1). Lawrence Erlbaum Associates.

Cedran, D. P., Cedran, J. C., \& Kiouranis, N. M. M. (2018). A importância da simbologia no ensino de química e suas correlações com os aspectos macroscópicos e moleculares. Revista de Ensino de Ciências e Matemática, 9(4), 38-57. https://doi.org/10.26843/. v9i4.13cedr42

Chin, C., \& Brown, D. (2000) Learning in Science: A Comparison of Deep and Surface Approaches. Journal of Research in Science Teaching. 37(2), 109-138. https://doi. org/10.1002/(SICI)1098-2736(200002)37:2<109::AID-TEA3>3.0.CO;2-7

Chittleborough, G., \& Treagust, D. (2008). Correct interpretation of chemical diagrams requires transforming from one level of representation to another. Research in science education, 38(4), 463-482. https://doi.org/10.1007/s11165-007-9059-4

Ferk S. V., Vrtacnik, M., Blejec, A., \& Gril, A. (2003). Students' understanding of molecular structure representations. International Journal of Science Education, 25(10), 1227-1245. https://doi.org/10.1080/0950069022000038231

Flavell, J. H. (1976). Metacognitive Aspects of Problem Solving. In L. B. Resnick (Ed.), The Nature of Intelligence, 231-235.

Flavell, J. H. (1979). Metacognition and cognitive monitoring: A new area of cognitive-developmental inquiry. American psychologist, 34(10), 906-911. https://doi. org/10.1037/0003-066X.34.10.906

Flôr, C. C., \& Cassiani, S. (2016). Qual Química ensinar? Reflexões a respeito da educação Química e formação de leitores em aulas de Química no Ensino Médio. Reflexão e Ação, 24(1), 366-381. http://dx.doi.org/10.17058/rea.v24i1.3873 
Francisco Junior, W. E. (2008). Uma abordagem problematizadora para o ensino de interações intermoleculares e conceitos afins. Química Nova na Escola, (29), 20-23.

Gibin, G. B., \& Ferreira, L. H. (2010). A formação inicial em química baseada em conceitos representados por meio de modelos mentais. Química Nova, 33(8), 18091814. https://doi.org/10.1590/S0100-40422010000800033

Gilbert, J. K. (2008). Visualization: An emergent field of practice and enquiry in science education. In Visualization: Theory and practice in science education, 3-24. Springer, Dordrecht. https://doi.org/10.1007/978-1-4020-5267-5_1

Gilbert, J. K., Justi, R., \& Queiroz, A. S.(2009). The use of modelling to develop visualization during the learning of ionic bonding. VIII Confererence of the European Science Education Research Association Conference.

Gilbert, J. K., \& Treagust, D. F. (2009). Introduction: Macro, submicro and symbolic representations and the relationship between them: Key models in chemical education. In Multiple representations in chemical education, 1-8. Springer, Dordrecht. https://doi. org/10.1007/978-1-4020-8872-8_1

Gobert J. D. (2005) Leveraging Technology and Cognitive Theory on Visualization to Promote Students' Science. In J. K. Gilbert (eds) Visualization in Science Education. Models and Modeling in Science Education, vol. 1, 73-90. Springer, Dordrecht. https:// doi.org/10.1007/1-4020-3613-2_6

Gomez, M. A., Pozo, J. I., \& Sanz A. (1995) Students'ideas on conservation of matter. Effects of expertise and context variables. Science Education, 79(1), 77-93. https://doi. org/10.1002/sce.3730790106

Johnstone, A. H. (1993). The development of chemistry teaching: A changing response to changing demand. Journal of chemical education, 70(9), 701-705. https://doi. org/10.1021/ed070p701

Keiner, L. \& Graulich, N. (2019). Transitions between representational levels: characterization of organic chemistry students' mechanistic features when reasoning about laboratory work-up procedures. Chemistry Educational Research and Practice, 1-14. https://doi.org/10.1039/C9RP00241C

Kozma, R., \& Russel, J. (2005). Pupils Becoming Chemists. Developing Representational Competence. In J. K. Gilbert (eds). Visualization in Science Education. Springer. 121-146.

Locatelli, S.W., \& Arroio, A. (2011). Desenhando moléculas e pensando sobre elas: habilidade metavisual no ensino de isomeria geométrica. Revista Brasileira de Ensino de Química, 6, 99-112.

Locatelli, S. W., \& Arroio, A. (2014). Metavisual strategy assisting the learning of initial concepts of electrochemistry. Natural Science Education, 1(39), 14-24. 
Locatelli, S. W., \& Arroio, A. (2017). Dificuldades na transição entre os níveis simbólico e submicro-repensar o macro pode auxiliar a compreender reações químicas? Enseñanza de las ciencias, (Extra), 4239-4244.

Moraes, R. (2003). Uma tempestade de luz: a compreensão possibilitada pela análise textual discursiva. Ciência \& Educação (Bauru), 9(2), 191-211. https://doi.org/10.1590/ S1516-73132003000200004

Mortimer, E. F. (2000). Linguagem e formação de conceitos no ensino de ciências. UFMG. Pauletti, F., Rosa, M. P. A., \& Catelli, F. (2014). A importância da utilização de estratégias de ensino envolvendo os três níveis de representação da Química. Revista Brasileira de Ensino de Ciência e Tecnologia, 7(3), 121-134. https://dx.doi.org/10.3895/S1982873X2014000300008

Rapp, D. N., \& Kurby, C. A. (2008). The 'ins' and 'outs' of learning: Internal representations and external visualizations. In Visualization: Theory and practice in science education (pp. 29-52). Springer, Dordrecht. https://doi.org/10.1007/978-1-4020-5267-5_2

Ribeiro, C. (2003). Metacognição: um apoio ao processo de aprendizagem. Psicologia: reflexão e crítica, 16(1), 109-116. https://doi.org/10.1590/S0102-79722003000100011

Rickey, D., \& Stacy, A. M. (2000). The role of metacognition in learning chemistry. Journal of Chemical Education, 77(7), 915-920. https://doi.org/10.1021/ed077p915

Rodrigues, S. B. D. V., Da-Silva, D. C., \& Quadros, A. L. D. (2011). O ensino superior de química: Reflexões a partir de conceitos básicos para a química orgânica. Química Nova, 34(10), 1840-1845. http://dx.doi.org/10.1590/S0100-40422011001000019

Roque, N. F., \& Silva, J. L. P. (2008). A linguagem química e o ensino da química orgânica. Química nova, 31(4), 921-923. http://dx.doi.org/10.1590/S0100-40422008000400034

Santos, V.C., \& Arroio, A. (2016). The representational levels: Influences and contributions to research in chemical education. Journal of Turkish Science Education, 13(1), 3-18. http://dx.doi.org/10.12973/tused.10153a

Santos, L. R. L., Lima, J. P. M., \& Sarmento, V. H. V (2017). Concepções de alunos ingressantes no curso de licenciatura em química sobre alguns conceitos de soluções. REnCiMa, 8(3), 41-60. http://dx.doi.org/10.26843/rencima.v8i3.1239

Schnetzler, R. P. (2002). A pesquisa em ensino de química no Brasil: Conquistas e perspectivas. Quimica nova, 25, 14-24. http://dx.doi.org/10.1590/S010040422002000800004

Taber, K. S. (2009). Learning at the symbolic level. In Multiple representations in chemical education (pp. 75-105). Springer, Dordrecht. https://doi.org/10.1007/978-1-4020-8872$8 \_5$ 
Teruya, L. C., Marson, G. A., Ferreira, C. R., \& Arroio, A. (2013). Visualização no ensino de química: pontamentos para a pesquisa e desenvolvimento de recursos educacionais. Química Nova, 36(4), 561-569. http://dx.doi.org/10.1590/s0100-40422013000400014

Wartha, E. J., Guzzi Filho, N. J., \& Jesus, R. M. (2012). O experimento da gota salina e os níveis de representação em química. Educación Química, 23(1), 55-61.

Wu, H. K., \& Shah, P. (2004). Exploring visuospatial thinking in chemistry learning. Science education, 88(3), 465-492. https://doi.org/10.1002/sce.10126.

\author{
Bruno Gumieri Fernandes \\ Universidade Federal do $A B C$ (UFABC) \\ Santo André, São Paulo, Brasil \\ bruno.gumieri16@gmail.com \\ Solange Wagner Locatelli \\ Universidade Federal do $A B C$ (UFABC) \\ Santo André, São Paulo, Brasil \\ solangeufabc@gmail.com
}

Editor Responsável

Stefannie Ibraim

Manifestação de Atenção às Boas Práticas Científicas e de Isenção de Interesse

Os autores declaram ter cuidado de aspectos éticos ao longo do desenvolvimento da pesquisa e não ter qualquer interesse concorrente ou relações pessoais que possam ter influenciado o trabalho relatado no texto. 